\title{
SYSGENET: a meeting report from a new European network for systems genetics
}

\author{
Klaus Schughart $\cdot$ SYSGENET consortium
}

Received: 22 April 2010/Accepted: 24 June 2010/Published online: 11 July 2010

(C) The Author(s) 2010. This article is published with open access at Springerlink.com

\begin{abstract}
The first scientific meeting of the newly established European SYSGENET network took place at the Helmholtz Centre for Infection Research (HZI) in Braunschweig, April 7-9, 2010. About 50 researchers working in the field of systems genetics using mouse genetic reference populations (GRP) participated in the meeting and exchanged their results, phenotyping approaches, and data analysis tools for studying systems genetics. In addition, the future of GRP resources and phenotyping in Europe was discussed.
\end{abstract}

\section{The SYSGENET network}

SYSGENET represents a network of scientists in Europe who use mouse genetic reference populations (GRP) to identify complex genetic factors that influence phenotypic traits. Studies with GRPs are expected to contribute to the discovery of principal biological processes and gene networks that are involved in disease phenotypes. The findings will be translated to human diseases and represent the basis for understanding disease etiology and developing new treatment strategies. These gene networks can be extended to other species as well.

The researchers in SYSGENET are using various GRPs as model systems to investigate the biological mechanisms and gene regulatory networks involved in disease phenotypes. This approach has been described in many reviews

Participants of the SYSGENET meeting are given in the appendix.

K. Schughart $(\bowtie)$

Department of Infection Genetics, Helmholtz Centre for

Infection Research, 38124 Braunschweig, Germany

e-mail: klaus.schughart@helmholtz-hzi.de and reports (Bao et al. 2006; Boon et al. 2009; Bystrykh et al. 2005; Chesler et al. 2005; Churchill et al. 2004; de Haan and Williams 2005; Dejager et al. 2009; Flint and Mott 2008; Gatti et al. 2007; Hovatta and Barlow 2008; Jansen and Nap 2001; Johannes et al. 2008; Li et al. 2005; Michaelson et al. 2009; Morahan et al. 2008b; Peirce et al. 2004; Peters et al. 2007; Roberts et al. 2007). The SYSGENET network partners are studying phenotypes relevant to infectious diseases, inflammatory disorders, metabolic diseases, cancer, neurological and psychiatric disorders, and infertility. The GRPs presently exploited by the network laboratories include inbred strains, consomic strains, recombinant inbred strains, congenic strains, interspecific recombinant congenic strains, outbred populations, and the upcoming large recombinant inbred strain collection known as the Collaborative Cross.

SYSGENET integrates the different national, European, and worldwide research programs in the field of complex genetics, systems biology, and the development of sophisticated experimental model systems. SYSGENET also reaches out to systems genetics programs in the United States and Australia.

The specific objectives of SYSGENET are

- to create a European network for systems genetics for complex genetic trait studies in mouse models by combining expertise and methods, exchanging results, and connecting the different ongoing national programs

- to link to research groups studying human complex genetic diseases

- to prepare concepts for a EU mouse resource infrastructure for GRPs

- to interact with worldwide systems genetics programs

- to prepare calls for research programs in the field of systems genetics in Europe 
SYSGENET is funded through the COST framework (http://www.cost.eu/about_cost). COST is an intergovernmental framework for European Cooperation in Science and Technology that promotes and coordinates nationally funded research in Europe, through funding of research networks. SYSGENET is coordinated by Klaus Schughart (Helmholtz Center for Infection Research, Braunschweig, Germany). More detailed information about SYSGENET can be obtained from the website http://www.helmholtzhzi.de/sysgenet/.

\section{Infectious diseases}

Infectious diseases continue to represent a threat to human health. Due to global warming and travel, newly emerging diseases are spreading at an unprecedented rate around the world. Examples are the dissemination of antibioticsresistant mycobacteria, the new swine influenza virus variant, SARS, and West Nile virus (WNV). Several research groups are using mouse GRPs to identify complex genetic influences on the host susceptibility to infections. GRPs have been and will continue to be an important basis for understanding infectious diseases in humans. A very good example for translational research was presented by Pascal Rihet, who identified genomic susceptibility regions to malaria in human populations in Africa (Delahaye et al. 2007) and then continued to compare these results with studies in mouse GRPs. In this way, a region on human chromosome 5 and its homologous regions on mouse chromosomes 11 and 18 were identified. Subsequent expression studies in mice will now help to determine the molecular networks and genes involved. Paul Denny described the mapping of genetic susceptibility to Streptococcus pneumonia infections in mouse inbred strains to chromosomes 7 (Denny et al. 2003) and 4 (unpublished). Infection susceptibility to influenza was described by Klaus Schughart, who also pointed out that high susceptibility includes a hyperreactive immune response in the host (Srivastava et al. 2009). Xavier Montagutelli generated a unique resource of Mus spretus $\times \mathrm{C} 57 \mathrm{BL} / 6 \mathrm{~J}$ interspecific recombinant congenic strains that carry different genomic fragments of $\mathrm{Mus}$ spretus on a C57BL/6 J background (Burgio et al. 2007). This GRP was used to identify resistance and susceptibility regions to various pathogens, including Rift Valley fever, West Nile virus, Yersinia pestis, and influenza. The first lines of the Collaborative Cross strains have been screened by Fuad Iraqi for a number of susceptibility loci to various pathogens (unpublished). It was remarkable to see that several quantitative trait loci (QTL) showed high significance and that the genomic intervals for several loci were very narrow, which should make it possible to identify quickly the underlying quantitative trait genes.

\section{Metabolic diseases}

Metabolic diseases in humans are dramatically on the rise; obesity and related diseases in particular represent a serious challenge to future health systems. Several groups addressed the complex genetics of metabolic functions and disorders using different mouse GRPs. Gudrun Brockmann reported on the mapping of QTLs for obesity in a specific mouse strain isolated in Berlin and the BXD congenic strain set (Neuschl et al. 2010). The future goal is to relate these QTLs to genetic polymorphisms that influence the immune system. Joan Campbell-Tofte presented the use of herbal extracts for the treatment of type 2 diabetes in humans. She nicely illustrated the use of mouse models: from human to mouse to humans and back to the mouse. Pénélope Andreux reported on the setting up of a mouse clinic in Lausanne for a systematic analysis of mouse GRPs for a large number of metabolic phenotypes, including mitochondrial functions (Koutnikova et al. 2009). Juan M. Falcon-Perez described the genomic, proteomic, and metabolic phenotyping capabilities of their technological platform and introduced extracellular microvesicles and metabolomic profiles as two new biological sources for identifying biomarkers for the detection and monitoring of hepatic diseases (Hackenberg et al. 2009). Abnormalities and diseases of the liver are also the subject of studies presented by Karl Kashofer (Kashofer et al. 2009). Several loci for (nonalcoholic) steatohepatitis have been mapped in chromosome substitution strains, and a more detailed mapping in subcongenic strains is ongoing.

\section{Behavior}

Although rats in general were the species of choice for use by experimental psychologists to study behavior, mice have been the preferred animal for behavior geneticists since at least the $1940 \mathrm{~s}$. In addition, the adaptation of behavioral assays and the development of new methods have confirmed the mouse as one of the most preferred experimental systems to learn more about the genetic underpinnings of behavior and associated phenotypes. Martien Kas described the currently underlying scientific rationale. Precise measurement of a well-described behavioral trait across a GRP will lead to the identification of associated genes and genomic regions. In the next step these genes can be used to find homologous genes and pathways that contribute to the development of neuropsychiatric disorders in humans. The translational value of this interspecies genetic approach was nicely 
exemplified in a study in which a QTL for avoidance behavior in mice was related to bipolar disorders in humans (de Mooij-van Malsen et al. 2009). In a similar approach, Iris Hovatta used a cross-species neurogenomics comparison to correlate brain region-specific gene expression patterns and anxiety-like behavior in mouse GRPs to polymorphisms in the Finnish population for anxiety disorders (Hovatta et al. 2005). The mouse genes allowed identification of potential candidate genes in humans who predispose to anxiety disorders. Paul Franken presented studies on the identification of genetic traits that influence homeostatic and circadian aspects of sleep, and the electroencephalogram in the BXD GRP and in inter- and backcross panels of mice (Shaw and Franken 2003). Several genes that play a decisive role were identified, and further phenotyping of the extended BXD GRP is planned. Eero Vasar and Sulev Kõks described the role of the $W f s l$ gene in knockout mice for anxiety behavior, an altered response to morphine and the release of striatal dopamine (Koks et al. 2009; Luuk et al. 2009). Ewelina Knapska reported the use of a highly sophisticated cage system, IntelliCage, to automatically record a number of different complex behavioral traits in mice (Jaholkowski et al. 2009). Mice can be housed in social groups but nevertheless tested individually. Ryszard Przewlocki reported on a systematic study on various inbred mouse strains to identify genetic determinants of alcohol and drug addiction (Piechota et al. 2010). Combining these studies with comprehensive gene expression analyses revealed that glucocorticoid receptor-activated gene expression pathways play an important role. Wim Crusio studied behavioral traits in learning and related them to brain anatomy (Crusio and Schwegler 2005). Thereby, the extent of neuron projections in the hippocampus could be correlated to more efficient learning capabilities and these two phenotypes are very strongly correlated genetically. Guus Smit gave an overview on a collaborative effort in the Netherlands in which several research groups have determined various behavioral phenotypic traits and QTLs in a commonly used BXD population (Loos et al. 2009). Also, they established a mouse facility in which they are using automated screening cages with sophisticated video recording and analysis.

\section{Cancer and liver cirrhosis}

Cancer is still one of the most frequent causes of death in Western countries, and understanding its molecular causes as well as establishing appropriate animal model systems for the development of new treatment strategies is very important. Fragiskos Kolisis reported on the setting up of an infrastructure for a systems biology approach to carcinogenesis and aging (Chatziioannou et al. 2009). Understanding proteasome function and dysfunction as well as studying the alterations of the genome and proteome that account for different cancer phenotypes in a mouse skin carcinogenesis model are among the research goals. Javier Santos used GRPs to identify genetic traits for the susceptibility to radiation-induced thymic lymphomas in interspecific recombinant congenic and consomic mouse strains (Santos et al. 2009). Frank Lammert developed assay systems to determine genetic causes of liver fibrosis and inflammatory liver carcinogens in the BXD mouse recombinant congenic GRP (Weber et al. 2008).

\section{Other}

Leonard Schalkwyk studied allele-specific methylation in humans (Schalkwyk et al. 2010). He estimated that potentially more than 35,000 sites in the genome exhibit allele-specific modifications, and of these $10 \%$ are not in cis, a number that largely exceeds the number of known imprinted loci. These findings suggest that individual genetic heterogeneity may be much larger than estimated thus far and may contribute to individual phenotypic differences. Jiri Forejt used inter-subspecific consomic strains (Gregorova et al. 2008) to investigate male sterility and its consequences for interspecies hybrid sterility (Mihola et al. 2009). Furthermore, in the livers of inter-subspecific hybrid strains he discovered new patterns of gene expression that were absent from both parental strains.

\section{Bioinformatic aspects of systems genetics}

The capture, storage, handling, and analysis of large data sets will present a specific challenge for future systems genetics projects. Ritsert Jansen and Pjotr Prins presented their approaches to integrate data from various phenotypic studies, encompassing gene expression, metabolome, and classical traits, and to develop new tools for advanced and improved mapping of QTLs (Jansen et al. 2009; Li et al. 2008; Swertz and Jansen 2007). These tools will be provided to the scientific community. Andreas Beyer gave a report on how to integrate data obtained at the post-transcriptional level with RNA expression data. Several loci that influence the post-transcriptional regulation of gene products could be identified in yeast. Steffen Möller presented his suite for the analysis of expression QTL (http://eqtl.berlios.de), which is being applied to the analysis of experimental autoimmune encephalomyelitis in mouse and rat. Anastasios Bezerianos presented a platform and developments for the identification of gene regulatory networks integrating protein-protein interactions and microarray data (Bezerianos and Maraziotis 2008). They started with yeast data and will soon expand to mouse, 
concentrating on time-varying gene regulatory networks. Morris Swertz presented XGAP, a software platform developed for data management and integration of large data sets from phenotyping and genotyping studies (Swertz et al. 2010). Grant Morahan described the development of an extended tool for WebQTL that allows a genome-centric analysis of QTL interactions (unpublished).

\section{Current status of the Collaborative Cross}

The Collaborative Cross (CC) is currently being generated as a community resource for more sensitive and refined mapping of QTLs. The goal is to breed a large population of recombinant inbred strains starting from eight founder strains. The eight founder strains were selected to capture a large portion of the genetic variation in the mouse genome. In fact, the genetic variation represented in the $\mathrm{CC}$ will be twice the genetic variation present in the human population (reviewed in Valdar et al. 2006). The three sites where the resource is being generated reported the present status of their breeding colonies; the final goal is to generate a total of 700 lines (Chesler et al. 2008; Iraqi et al. 2008; Morahan et al. 2008a). Grant Morahan gave an update on the "Southern Cross" being established in Perth, Australia. An inbreeding depression was observed at generations 7-9. At present, about 200 strains have been bred beyond generation 10. The first 40 strains are expected to be inbred by the end of the year. David Threadgill reported the status of the breeding colony at the University of North Carolina, Chapel Hill, NC, USA. About 300 lines are currently breeding at UNC. The first 50 recombinant inbred lines will be available by the end of this year and 200 lines by the end of 2011. To speed up the inbreeding process, markerassisted breeding will be used to create homozygous lines beyond generation 12 . Genome analysis demonstrated that all parental genomes are well represented in the advanced generations. The first phenotyping analysis showed a large variation in body weight, exercise propensity, and susceptibility to pathogens. Richard Mott described the genome structure of a smaller CC colony, funded by the Wellcome Trust, which was developed by Fuad Iraqi and is presently housed in Tel Aviv, Israel. A first phenotyping analysis for the QTLs that affect recombination frequencies was performed. A full-genome sequencing project to complete the parental strains with high coverage is underway at the Sanger Institute.

\section{Conclusion}

The two-day meeting in Braunschweig has clearly demonstrated the great value of mouse GRPs in identifying genetic determinants of complex genetic traits for various phenotypic traits related to diseases in humans. The partners of the network collectively have great expertise in disease phenotyping and analysis of genetic reference populations. Several examples that illustrated the translation of the knowledge gained in the mouse experimental systems to humans were presented. Links to clinical researchers already exist at several places but will have to be further expanded in the future. Furthermore, mouse GRPs can be ideally combined with mouse mutant lines carrying a gene-knockout mutation to determine the effect of a strong genetic defect in combination with modifier genes. It also became clear that a strong and sustained financial investment in mouse breeding and phenotyping facilities as well as in bioinformatic infrastructure is urgently needed to further advance a systems genetics approach in Europe.

Open Access This article is distributed under the terms of the Creative Commons Attribution Noncommercial License which permits any noncommercial use, distribution, and reproduction in any medium, provided the original author(s) and source are credited.

\section{Appendix}

www.helmholtz-hzi.de/sysgenet and participants of the meeting: Klaus Schughart, Helmholtz Center for Infection Research, Germany; Danny Arends, University of Groningen, Netherlands; Pénélope Andreux, Ecole Polytechnique Fédérale de Lausanne, Switzerland; Rudi Balling, University of Luxembourg, Luxembourg; Andreas Beyer, TU Dresden, Germany; Anastasios Bezerianos, Biosignal Processing Lab, Department of Medical Physics, Greece; Gudrun A. Brockmann, Humboldt University Berlin, Germany; Wim E. Crusio, University of Bordeaux and CNRS, France; Joan Campbell-Tofte, University of Copenhagen, Denmark; Paul Denny, MRC Mammalian Genetics Unit, UK; Juan M Falcon-Perez, CIC bioGUNE, CIBERehd, Spain; Jiri Forejt, Institute of Molecular Genetics, Academy of Sciences, Czech Republic; Paul Franken, Center for Integrative Genomics, University of Lausanne, Switzerland; Iiris Hovatta, University of Helsinki, Finland; Fuad Iraqi, Sackler Faculty of Medicine TelAviv University, Israel; Ritsert C Jansen, University of Groningen, Netherlands; Leszek Kaczmarek, Polish Academy of Sciences, Nencki Institute of Experimental Biology, Poland; Martien J. Kas, Department of Neuroscience and Pharmacology, University Medical Centre Utrecht, Netherlands; Karl Kashofer, Medical University of Graz, Austria; Ewelina Knapska, Nencki Institute, Poland; Fragiskos Kolisis, Institute of Biological Research and Biotechnology, National Hellenic Research Foundation, 
Greece; Sulev Kõks, University of Tartu, Estonia; Frank Lammert, Saarland University, Germany; Steffen Möller, University of Lübeck, Germany; Xavier Montagutelli, Institut Pasteur, France; Grant Morahan, The Western Australian Institute for Medical Research, Australia; Richard Mott, Wellcome Trust Centre for Human Genetics, Oxford, UK; Susanne Pfoertner, Helmholtz Center for Infection Research, Germany; Pjotr Prins, Wageningen University, Netherlands; Ryszard Przewlocki, Institute of Pharmacology, Poland; Annamari Ranki, University of Helsinki, Finland; Javier Santos, Centro de Biología Molecular Severo Ochoa-Universidad Autónoma de Madrid, Spain; Pascal Rihet, Aix-Marseille University, France; Leonard Schalkwyk, King's College London, UK; August B Smit, Center for Neurogenomics and Cognitive Research, Netherlands; Morris Swertz, EBI, UK; David Threadgill, North Carolina State University, USA; Eero Vasar, University of Tartu, Estonia; Kurt Zatloukal, Institute of Pathology, Medical University Graz, Austria.

\section{References}

Bao L, Wei L, Peirce JL, Homayouni R, Li H et al (2006) Combining gene expression QTL mapping and phenotypic spectrum analysis to uncover gene regulatory relationships. Mamm Genome 17:575-583

Bezerianos A, Maraziotis IA (2008) Computational models reconstruct gene regulatory networks. Mol Biosyst 4:993-1000

Boon AC, deBeauchamp J, Hollmann A, Luke J, Kotb M et al (2009) Host genetic variation affects resistance to infection with a highly pathogenic $\mathrm{H} 5 \mathrm{~N} 1$ influenza $\mathrm{A}$ virus in mice. $\mathrm{J}$ Virol 83:10417-10426

Burgio G, Szatanik M, Guenet JL, Arnau MR, Panthier JJ et al (2007) Interspecific recombinant congenic strains between C57BL/6 and mice of the Mus spretus species: a powerful tool to dissect genetic control of complex traits. Genetics 177:2321-2333

Bystrykh L, Weersing E, Dontje B, Sutton S, Pletcher MT et al (2005) Uncovering regulatory pathways that affect hematopoietic stem cell function using 'genetical genomics'. Nat Genet 37:225-232

Chatziioannou A, Moulos P, Kolisis FN (2009) Gene ARMADA: an integrated multi-analysis platform for microarray data implemented in MATLAB. BMC Bioinformatics 10:354

Chesler EJ, Lu L, Shou S, Qu Y, Gu J et al (2005) Complex trait analysis of gene expression uncovers polygenic and pleiotropic networks that modulate nervous system function. Nat Genet 37:233-242

Chesler EJ, Miller DR, Branstetter LR, Galloway LD, Jackson BL et al (2008) The collaborative cross at oak ridge national laboratory: developing a powerful resource for systems genetics. Mamm Genome 19:382-389

Churchill GA, Airey DC, Allayee H, Angel JM, Attie AD et al (2004) The collaborative cross, a community resource for the genetic analysis of complex traits. Nat Genet 36:1133-1137

Crusio WE, Schwegler H (2005) Learning spatial orientation tasks in the radial-maze and structural variation in the hippocampus in inbred mice. Behav Brain Funct 1:3

de Haan G, Williams RW (2005) A genetic and genomic approach to identify longevity genes in mice. Mech Ageing Dev 126: $133-138$ de Mooij-van Malsen AJ, van Lith HA, Oppelaar H, Hendriks J, de Wit $\mathrm{M}$ et al (2009) Interspecies trait genetics reveals association of Adcy 8 with mouse avoidance behavior and a human mood disorder. Biol Psychiatr 66:1123-1130

Dejager L, Libert C, Montagutelli X (2009) Thirty years of Mus spretus: a promising future. Trends Genet 25(5):234-241

Delahaye NF, Barbier M, Fumoux F, Rihet P (2007) Association analyses of NCR3 polymorphisms with $P$. falciparum mild malaria. Microbes Infect 9:160-166

Denny P, Hopes E, Gingles N, Broman KW, McPheat W et al (2003) A major locus conferring susceptibility to infection by Streptococcus pneumoniae in mice. Mamm Genome 14:448-453

Flint J, Mott R (2008) Applying mouse complex-trait resources to behavioural genetics. Nature 456:724-727

Gatti D, Maki A, Chesler EJ, Kirova R, Kosyk O et al (2007) Genome-level analysis of genetic regulation of liver gene expression networks. Hepatology 46:548-557

Gregorova S, Divina P, Storchova R, Trachtulec Z, Fotopulosova V et al (2008) Mouse consomic strains: exploiting genetic divergence between Mus m. musculus and Mus m. domesticus subspecies. Genome Res 18:509-515

Hackenberg M, Sturm M, Langenberger D, Falcon-Perez JM, Aransay AM (2009) miRanalyzer: a microRNA detection and analysis tool for next-generation sequencing experiments. Nucl Acids Res 37:W68-W76

Hovatta I, Barlow C (2008) Molecular genetics of anxiety in mice and men. Ann Med 40:92-109

Hovatta I, Tennant RS, Helton R, Marr RA, Singer O et al (2005) Glyoxalase 1 and glutathione reductase 1 regulate anxiety in mice. Nature 438:662-666

Iraqi FA, Churchill G, Mott R (2008) The collaborative cross, developing a resource for mammalian systems genetics: a status report of the wellcome trust cohort. Mamm Genome 19: 379-381

Jaholkowski P, Kiryk A, Jedynak P, Ben Abdallah NM, Knapska E et al (2009) New hippocampal neurons are not obligatory for memory formation; cyclin D2 knockout mice with no adult brain neurogenesis show learning. Learn Mem 16:439-451

Jansen RC, Nap JP (2001) Genetical genomics: the added value from segregation. Trends Genet 17:388-391

Jansen RC, Tesson BM, Fu J, Yang Y, McIntyre LM (2009) Defining gene and QTL networks. Curr Opin Plant Biol 12:241-246

Johannes F, Colot V, Jansen RC (2008) Epigenome dynamics: a quantitative genetics perspective. Nat Rev Genet 9:883-890

Kashofer K, Tschernatsch MM, Mischinger HJ, Iberer F, Zatloukal K (2009) The disease relevance of human hepatocellular xenograft models: molecular characterization and review of the literature. Cancer Lett 286:121-128

Koks S, Soomets U, Paya-Cano JL, Fernandes C, Luuk H et al (2009) $W f_{s} 1$ gene deletion causes growth retardation in mice and interferes with the growth hormone pathway. Physiol Genomics 37:249-259

Koutnikova H, Laakso M, Lu L, Combe R, Paananen J et al (2009) Identification of the UBP1 locus as a critical blood pressure determinant using a combination of mouse and human genetics. PLoS Genet 5:e1000591

Li H, Lu L, Manly KF, Chesler EJ, Bao L et al (2005) Inferring gene transcriptional modulatory relations: a genetical genomics approach. Hum Mol Genet 14:1119-1125

Li Y, Breitling R, Jansen RC (2008) Generalizing genetical genomics: getting added value from environmental perturbation. Trends Genet 24:518-524

Loos M, van der Sluis S, Bochdanovits Z, van Zutphen IJ, Pattij T et al (2009) Activity and impulsive action are controlled by different genetic and environmental factors. Genes Brain Behav $8: 817-828$ 
Luuk H, Plaas M, Raud S, Innos J, Sutt S et al (2009) Wfs 1-deficient mice display impaired behavioural adaptation in stressful environment. Behav Brain Res 198:334-345

Michaelson JJ, Loguercio S, Beyer A (2009) Detection and interpretation of expression quantitative trait loci (eQTL). Methods 48:265-276

Mihola O, Trachtulec Z, Vlcek C, Schimenti JC, Forejt J (2009) A mouse speciation gene encodes a meiotic histone $\mathrm{H} 3$ methyltransferase. Science 323:373-375

Morahan G, Balmer L, Monley D (2008a) Establishment of "The Gene Mine": a resource for rapid identification of complex trait genes. Mamm Genome 19:390-393

Morahan G, Peeva V, Mehta M, Williams R (2008b) Systems genetics can provide new insights into immune regulation and autoimmunity. J Autoimmun 31:233-236

Neuschl C, Hantschel C, Wagener A, Schmitt AO, Illig T et al (2010) A unique genetic defect on chromosome 3 is responsible for juvenile obesity in the Berlin Fat Mouse. Int $\mathrm{J}$ Obes (Lond). Epub ahead of print

Peirce JL, Lu L, Gu J, Silver LM, Williams RW (2004) A new set of BXD recombinant inbred lines from advanced intercross populations in mice. BMC Genet 5:7

Peters LL, Robledo RF, Bult CJ, Churchill GA, Paigen BJ et al (2007) The mouse as a model for human biology: a resource guide for complex trait analysis. Nat Rev Genet 8:58-69

Piechota M, Korostynski M, Solecki W, Gieryk A, Slezak M et al (2010) The dissection of transcriptional modules regulated by various drugs of abuse in the mouse striatum. Genome Biol $11: R 48$

Roberts A, Pardo-Manuel de Villena F, Wang W, McMillan L, Threadgill DW (2007) The polymorphism architecture of mouse genetic resources elucidated using genome-wide resequencing data: implications for QTL discovery and systems genetics. Mamm Genome 18:473-481

Santos J, Gonzalez-Sanchez L, Matabuena-Deyzaguirre M, VillaMorales M, Cozar P et al (2009) A role for stroma-derived annexin $\mathrm{A} 1$ as mediator in the control of genetic susceptibility to T-cell lymphoblastic malignancies through prostaglandin E2 secretion. Cancer Res 69:2577-2587

Schalkwyk LC, Meaburn EL, Smith R, Dempster EL, Jeffries AR et al (2010) Allelic skewing of DNA methylation is widespread across the genome. Am J Hum Genet 86:196-212

Shaw PJ, Franken P (2003) Perchance to dream: solving the mystery of sleep through genetic analysis. J Neurobiol 54:179-202

Srivastava B, Blazejewska P, Hessmann M, Bruder D, Geffers R et al (2009) Host genetic background strongly influences the response to influenza a virus infections. PLoS ONE 4:e4857

Swertz MA, Jansen RC (2007) Beyond standardization: dynamic software infrastructures for systems biology. Nat Rev Genet 8:235-243

Swertz MA, Velde KJ, Tesson BM, Scheltema RA, Arends D et al (2010) XGAP: a uniform and extensible data model and software platform for genotype and phenotype experiments. Genome Biol 11:R27

Valdar W, Flint J, Mott R (2006) Simulating the collaborative cross: power of quantitative trait loci detection and mapping resolution in large sets of recombinant inbred strains of mice. Genetics 172:1783-1797

Weber S, Gressner OA, Hall R, Grunhage F, Lammert F (2008) Genetic determinants in hepatic fibrosis: from experimental models to fibrogenic gene signatures in humans. Clin Liver Dis 12:747-757 vii 